\title{
ANALISIS KONDISI FISIK ATLIT POMNAS CABANG OLAHRAGA BULUTANGKIS MALUKU UTARA TAHUN 2019
}

\author{
Muliadi Muin ${ }^{1}$, Ardiansyah Nur ${ }^{2}$, Alief Lam Akhmady ${ }^{3}$ \\ ${ }^{1}$ STKIP Kie Raha Ternate, ${ }^{2}$ FKIP Universitas Muhammadiyah Luwuk, ${ }^{3}$ STKIP Kie Raha Ternate \\ ardiansyahnur122@yahoo.com
}

\begin{abstract}
This study aims to determine the physical condition of POMNAS athletes in North Maluku badminton sport in 2019. This type of research is quantitative descriptive. The subjects of this study were all athletes who participated in POMNAS of North Maluku badminton sport as many as 4 people. Data collection techniques using tests and measurements namely physical condition tests which include: a) strength (muscle strength of the fingers, arm and shoulder muscle strength, leg muscle strength, back muscle strength), b) explosive power (arm and shoulder explosive power, leg muscle explosiveness, c) flexibility, d) speed, e) muscle endurance (stomach muscle endurance, arm and shoulder muscle endurance, leg muscle endurance and f) heart-lung endurance. The results of the study illustrate that the average level of physical condition of the North Maluku sports branch of POMNAS in 2019 is in the good category
\end{abstract}

\section{Keywords: Physical Conditions, Badminton, POMNAS Athletes}

Penelitian ini bertujuan untuk mengetahui kondisi fisik atlit POMNAS cabang olahraga bulutangkis Maluku Utara Tahun 2019. Jenis penelitian ini adalah deskriptif kuantitatif. Subjek penelitian ini adalah seluruh atlit yang mengikuti POMNAS cabang olahraga bulutangkis Maluku Utara sebanyak 4 orang. Teknik pengambilan data dengan menggunakan tes dan pengukuran yaitu Tes kondisi fisik yang meliputi: a) kekuatan (kekuatan otot jari tangan, kekuatan otot lengan dan bahu, kekuatan otot tungkai, kekuatan otot punggung), b) daya ledak (daya ledak lengan dan bahu, daya ledak otot tungkai), c) kelentukan, d) kecepatan, e) daya tahan otot (daya tahan otot perut, daya tahan otot lengan dan bahu, daya tahan otot tungkai dan f) daya tahan jantung-paru. Hasil penelitian menggambarkan bahwa rata-rata tingkat kondisi fisik atlit POMNAS cabang olahraga Maluku Utara Tahun 2019 berada pada kategori baik.

\section{Kata Kunci: Kondisi Fisik, Bulu Tangkis, Atlit POMNAS}

\section{PENDAHULUAN}

Olahraga bulutangkis merupakan cabang olahraga permainan yang digemari oleh masyarakat Indonesia, baik laki-laki maupun perempuan, mulai dari anak-anak hingga dewasa baik di daerah maupun di kotakota besar. Hal ini ditunnjukkan dengan banyaknya masyarakat yang bermain bulutangkis baik di ruangan tertutup (indoor) dan lapangan terbuka (outdoor). Orang-orang yang melakukan permainan ini dengan berbagai tujuan diantaranya adalah sebagai 1) olahraga rekreasi, 2) olahraga pendidikan, 3) olahraga kesehatan atau media untuk meningkatkan kesegaran jasmani, dan 4) olahraga prestasi (Takwin, 2015:2).
Kondisi fisik adalah proses mengembangkan kemampuan aktivitas gerak jasmani yang dilakukan secara sistematik dan ditingkatkan secara progresif untuk mempertahankan atau meningkatkan derajat kebugaran jasmani agar tercapai kemampuan kerja fisik yang optimal. Tujuan utamanya adalah untuk meningkatkan potensi fungsional atlet dan mengembangkan kemampuan biomotor ke derajat yang paling tinggi (Takwin, 2015:3).

Hal ini sejalan apa yang dikemukakan Sajoto (1988:57) bahwa Setiap usaha meningkatkan kondisi fisik, maka perlu pengembangan semua komponen tersebut, walaupun perlu dilaksanakan dengan sistem prioritas (komponen apa saja yang perlu 
mendapat porsi latihan yang lebih besar dibandingkan kompenen lain).

Lebih lanjut lagi menurut Harsono (1988:153) menyatakan bahwa kondisi fisik atlet memegang peranan yang sangat penting dalam program latihannya. Program latihan kondisi fisik haruslah direncanakan secara baik dan sistematis dan ditujukan untuk meningkatkan kesegaran jasmani dan kemampuan fungsional dari sistem tubuh sehingga dengan demikian memungkinkan atlet untuk mencapai prestasi yang lebih baik.

Kondisi fisik merupakan unsur yang sangat penting hampir diseluruh cabang olahraga. Oleh karena itu latihan kondisi fisik perlu mendapat perhatian yang serius direncanakan dengan matang dan sistematis, sehingga tingkat kesegaran jasmani dan kemampuan fungsional alat-alat tubuh lebih baik. Apabila kodisi fisik baik, maka : (a) Akan ada peningkatan dalam kemampuan sistem sirkulasi dan kerja jantung. (b) Terjadi peningkatan dalam kekuatan, kelentukan, stamina, kecepatan, dan komponen kondisi fisik lainnya. (c) Akan meningkatkan efektifitas dan efisiensi gerak kearah yang lebih baik. (d) Waktu pemulihan akan lebih cepat. (e) Respon bergerak lebih cepat apabila dibutuhkan.

Menurut L. A. Larson dan R.D. Yocom (1951) dalam buku M. A. Pasau (2012:119) mengumukakan bahwa: prestasi olahraga secara umum ditentukan oleh 10 komponen kemampuan kecakapan gerak (motor abylity), yaitu kekuatan, kecepatan, kelincahan, koordinasi, daya tahan otot, tenaga (Power), kelentukan, keseimbangan, daya tahan kerja jantung dan paru-paru, ketepatan dan kesehatan.

Menurut

Sajoto

(1988:58), mengemukakan bahwa kekuatan adalah komponen fisik yang menyangkut kemampuan seseorang pada saat mempergunakan ototototnya menerima beban dalam waktu kerja tersebut. Sehingga kekuatan lengan merupakan potensi fisik yang perlu dikembangkan sesuai dengan kebutuhan pada gerakan servis panjang bulutangkis. Makin komplit gerak yang dilakukan, makin besar pula tingkatan koordinasi yang diperlukan.

Salah satu bentuk latihan kekuatan dengan kontraksi isotonik yang paling popular adalah melalui program Weight Training. Menurut Harsono (1988 : 185) weight training adalah latihan-latihan yang sistematis dimana beban hanya dipakai sebagai alat untuk menambah tahanan terhadap kontraksi otot guna mencapai berbagai tujuan tertentu, seperti untuk meningkatkan dan menjaga kondisi fisik, kesehatan, kekuatan atau prestasi dalam suatu cabang olahraga tertentu. Merujuk pendapat Harsono dalam mencapai prestasi baik dibutuhkan latihan sistematis agar tingkat kondisi fisik lebih baik, maka seorang atlet sangat dianjurkan mempergunakan sistem weight traning.

Kekuatan otot merupakan komponen biomotorik yang diperlukan oleh semua cabang olahraga dengan tingkatan yang berbeda satu dengan lainnya. Komponen ini dapat ditingkatkan dengan cara memberikan tahanan yang internal maupun yang eksternal terhadap otot yang bersangkutan. Tahanan internal berupa, tahanan dari dalam tubuh sendiri, dimana kontraksi sekelompok otot dihambat atau dilawankan dengan kontraksi kelompok otot lainnya. Sedangkan tahanan eksternal, tahanan dari luar tubuh dapat berupa melawan orang lain (saling menarik, saling mendorong dan lain-lain). Mendorong tembok, menggunakan alat berbentuk dumbel, barbel, halter, peralatan olahraga atau bentuk beban lainnya (peralatan mesin dipusan kebugaran fisik). Termasuk juga dalam latihan eksternal, berat badan diri sendiri ketika melakukan gerakan baring-duduk (sit-up), gantung angkat badan (pull-up) dan lain-lain (Halim, 2011:27).

Kekuatan otot lengan adalah kemampuan seseorang dalam mempergunakan kekuatan maksimal dari otot lengan dalam mengeluarkan seluruh potensi atau kekuatan yang ada pada periode yang singkat. Pada tubuh manusia terdapat otot yang berfungsi sebagai alat yang menggerakan tubuh manusa secara aktif. Karena tanpa adanya otot, mata tulang-tulang yang ada pada tubuh manusia tidaklah mampu digerakan (Yunus, 1992:195 dalam Yusuf). Kekuatan otot lengan dibutuhkan sebagai tenaga pendorong pada saat melakukan pukulan. Semakin besar kekuatan otot lengan yang dihasilkan maka semakin keras pula pukulan yang dihasilkan (Yusuf, 2015:2). 
Menurut Bucher (Harsono, 1988:199) dikatakan bahwa seorang individu yang mempunyai power adalah orang yang memiliki : (a) derajat kekuatan otot yang tinggi, (b) derajat kecepatan yang tinggi, dan (c) derajat yang tinggi dalam keterampilan mengabungkan kecepatan dan kekuatan otot.

Unsur penting dalam power yaitu a). kekuatan otot, b) kecepatan otot dalam mengerahkan tenaga maksimal untuk mengatasi tahanan. Dengan demikian secara ringkas dapat kita simpulkan batasan power sebagai berikut: Power adalah kemampuan otot untuk megerhkan kekuatan maksimal dalam waktu yang sangat cepat. Oleh karena itu, latihan power wight traning tidak boleh hanya menekankan pada beban, akan tetapi harus pula pada kecepatan mengakat, mendorong dan menarik beban.

Kelentukan ini sangat diperlukan oleh setiap atlet agar mereka mudah untuk mempelajari berbagai gerak, meningkatkan keterampilan, mengurangi resiko cedera, dan mengoptimalkan kekuatan, kecepatan, dan koordinasi. Harsono (1988: 164) bahwa kelentukan dapat dikembangkan melalui latihan peregangan (stretching), yang modelnya terdiri atas: a) Peregangan dinamik (Dynamic stretch), b) Peregangan statik (Static stretch), c) Peregangan pasif, dan d) Proprioceptive Neuromuscular Facilitation (PNF).

Kecepatan adalah kemampuan untuk melakukan gerakan-gerakan yang sejenis secara berturut-turut dalam waktu yang sesingkat-singkatnya, atau kemampuan untuk menempuh suatu jarak dalam waktu yang sesingkat-singkatnya Harsono (1988:216).

Latihan kecepatan sebaiknya diberikan pada program pre-season setelah atlet memiliki kekuatan, kelentukan, dan daya tahan yang cukup (Harsono, 1988:18). Metode dan bentuk latihan untuk kecepatan antara lain : Metode latihan yang tepat untuk meningkatkan kemampuan Kecepatan gerak yang secara ekslusif hanya $10 \%$ adalah dengan Metode Repetisi (Repetition Method).

Daya tahan atau ketahan dalam dunia olahraga dikenal sebagai kemampuan peralatan organ tubuh olahrgawan untuk melawan kelelahan selam berlansungnya aktivitas atau kerja, lebih lanjut, seperti yang diungkapkan Harsono (1988:155) mengenai pengertian daya tahan adalah kedaan kondisi tubuh yang mampu untuk bekerja untuk waktu yang lama, tampa mengalami kelelahan yang berlebihan setelah menyelesaikan pekerjaan tersebut. Yang dimaksud dengan daya tahan dalam uraian dibawah ini adalah daya tahan sirkulatori-respiratori (circulatory-respiratory endurance). atau ada yang menyebut cardiovasuler endurance.

Daya tahan adalah kemampuan seseorang untuk melakukan kerja dalam waktu yang relatif lama. Daya tahan jantungpernapasan-peredaran darah (respiratoricardio-vasculatoir endurance). Peningkatan daya tahan jantung-pernapasan-peredaran darah terutama dapat dicapai melalui peningkatan tenaga aerobik maksimal $\left(\mathrm{VO}_{2^{-}}\right.$ Max) dan ambang anaerobik. sebaiknya untuk meningkatkan $\mathrm{VO}_{2}$-Max dilakukan latihan anaerobik dengan interval istirahat. Maka dari itu, pelaksanaan latihan daya tahan jantungpernapasan-peredaran darah selalu terkait dengan tenaga aerobik dan anaerobik, yang mana unsur tersebut selalu terkait pula dengan sistem energi yang diperlukan. Hal di atas tidak akan banyak dijelaskan disini oleh penulis, karena akan dijelaskan dalam materi ilmu faal olahraga dalam (Takwin, 2015:17).

Soekarman (1987) Online Bentuk latihan daya tahan jantung-pernapasanperedaran darah dapat dilaksanakan melalui : (a) Lari cepat sekali, (b) Lari cepat yang kontinu, (c) Lari lambat yang kontinu, (d) Lari dengan interval, (e) Latihan interval, (f) Jogging, (g) lari cepat ulang, (h) Fartlek atau speed play adalah suatu sistem latihan endurance yang maksudnya untuk membangun, mengembalikan atau memulihkan kondisi tubuh seorang atlet. Sedangkan latihan interval adalah suatu sistem latihan endurance yang maksudnya untuk memperkembangkan stamina atlet.

Menurut Sarwono (1990:34), bahwa ada empat komponen tekhnik dasar dalam ketermpilan bermain bulutangkis sebagai berikut: a) Tehnik memegang raket, b) Tehnik mengatur kerja kaki (foot work), c) Tehnik memukul bola, dan d) Tehnik menguasai polapola serangan dan pertahanan. sedangkan menurut PB. PBSI (1985:63) mengemukakan bahwa tekhnik dasar permainan bulutangkis 
adalah sebagai berikut: a) Pukulan Servis, b) Pukulan $l o b$, c) Pukulan Dropshot, d) Pukulan Smash e) Pukulan Drive

\section{METODE PENELITIAN}

Penelitian ini merupakan penelitian deskriptif kuantitatif yang bertujuan untuk mengetuhi tingkat kondisi fisik dan keterampilan bermain bulutangkis atlit POMNAS Maluku Utara cabang olahraga bulutangkis. Subjek penelitian ini adalah seluruh atlit yang mengikuti POMNAS cabang olahraga bulutangkis Maluku Utara sebanyak 4 orang. Pengambilan sampel dilakukan dengan menggunakan sampling jenuh. Sugiyono (2014:34) mengatakan bahwa sampling jenuh adalah teknik penentuan sampel bila semua anggota populasi digunakan sebagai sampel.

Teknik pengambilan data dengan menggunakan tes dan pengukuran yaitu Tes kondisi fisik yang meliputi: a) kekuatan (tes kekuatan otot jari tangan dengan menggunakan alat handgrip, tes kekuatan otot lengan dan bahu dengan mengunakan alat push and pull dynamometer, tes kekuatan otot tungkai dan tes kekuatan otot tungkai dengan menggunakan alat leg and back dynamometer), b) tes daya ledak (daya ledak lengan dan bahu dengan menggunakan tes lempar bola medicine, daya ledak otot tungkai dengan menggunakan tes verical jump), c) kelentukan dengan menggunakan flexiometer test, d) kecepatan dengan menggunakan tes lari sprint 40 meter, e) daya tahan otot (daya tahan otot perut dengan menggunakan tes sit$u p$, daya tahan otot lengan dan bahu dengan menggunakan tes push-up, daya tahan otot tungkai dengan menggunakan tes squat jump dan f) daya tahan jantung-paru dengan menggunakan bleep test.

Dalam penelitian ini penulis menggunakan rancangan analisis deskriftif dengan cara mengklarifikasikan nilai yang dicapai masing-masing atlet dalam tes. Kondisi fisik dan keterampilan, kemudian dari nilai tesebut dijumlah dan dilakukan pengkategorisasian berdasarkan rentang nilai (score). Untuk tes kekuatan fisik dilakukan pengukuran masing-masing variabel berdasarkan instrumet yang digunakan, lalu hasil pengukuran score yang didapat dari masing-masing variabel tersebut diberikan nilai berdasarkan pembagian kategori dan nilai konversi ini:

\section{Tabel 1. Rentang skor Kategori Kondisi} fisik (Putra)

\begin{tabular}{|c|c|c|c|c|c|c|c|}
\hline \multirow{2}{*}{ No } & \multirow{2}{*}{ KOMPONEN } & \multirow{2}{*}{ IEKNIK PENGUKURAN } & \multicolumn{5}{|c|}{ KATEGOR } \\
\hline & & & KURANG & CUKUP & BAIK & BAIK SEKALI & SEIPURNA \\
\hline \multirow[t]{5}{*}{1} & KEKUATAN & & & & & & \\
\hline & a. Chot Jai Tangan & Hand Gip Dymanometer & 23.29 & 30.36 & 37.43 & 44.50 & $>51$ \\
\hline & b. Ohot lengan dan Bahu & Push and Pull Dynamomete & 23.29 & 30.36 & 37.43 & 44.50 & $>51$ \\
\hline & c. Otoi Tungkai & Leg Dynamometer & $77 .-145$ & 146. -214 & $215 \cdot 202$ & $>283$ & \\
\hline & d. Chat Pungegung & Back Dyamometer & 59.795 & $80 .-100.5$ & $101 .-122$ & $1225 \cdot 143$ & $>143.5$ \\
\hline \multirow[t]{4}{*}{2} & DAYATAHANOTOT & & & & & & \\
\hline & a. Otot Pent & Situp & 20.29 & 30.49 & 50.69 & 70.89 & $>90$ \\
\hline & b. Cotal engan dan Bahu & Push lo & 4. -11 & $12 \cdot-19$ & $20 .-28$ & 29.37 & $>38$ \\
\hline & c. Oot Tungkai & Hat Squat Jump & 4. 24 & 25.45 & 46.66 & 67.68 & 288 \\
\hline 3 & KECEPATAN & Lai $40 \mathrm{~m}$ & 9.8 & 79.6 .9 & $6.8 \cdot 5.6$ & 5.7 .4 .7 & $>4.6$ \\
\hline 4 & FLEKS BBLLTTAS & Fexometer & 1.5 & 6.11 & 12.17 & 18.23 & $>24$ \\
\hline \multirow[t]{3}{*}{5} & POWER & & & & & & \\
\hline & a. Cot Lengan dean Barus & Medicne Bal & $2.63-3.67$ & $3.68-4.52$ & $4.53 \cdot 5.37$ & $5.38-5.22$ & $\times 6.23$ \\
\hline & b. Cou Tungka & Varciad Jump & $38-45$ & 40.52 & 53.61 & 62.69 & $>70$ \\
\hline 6 & DAYATAHANUNUNI & Test Bleep & $<35.0$ & $35.0-39.9$ & $40.5-45,1$ & $45.2 \cdot 50.9$ & $51.0-55.9$ \\
\hline
\end{tabular}

\section{Sumber: KONI Sulawesi Selatan 2015 \\ dalam Takwin, 2015:52}

\begin{tabular}{|c|c|c|}
\hline \multicolumn{3}{|c|}{ Tabel 2. Pembagian Kategori dan Nilai Konversi } \\
\hline NO & KATEGORI & KONVERSI NILAI \\
\hline 1 & SEMPURNA & $>10$ \\
\hline 2 & BAIK SEKALI & $8 .-9$ \\
\hline 3 & BAIK & $6 .-7$ \\
\hline 4 & CUKUP & $4 .-5$ \\
\hline 5 & KURANG & $<2$ \\
\hline Sumber: KONI Sulawesi Selatan 2015 dalam Takwin, 2015:52
\end{tabular}

\section{HASIL PENELITIAN}

Data hasil penelitian diperoleh yaitu kondisi fisik atlet bulutangkis Maluku Utara pada POMNAS tahun 2019 dari beberapa komponen fisik yang diujukan yaitu, kekuatan, daya ledak, kelentukan, kecepatan, daya tahan otot, dan daya tahan jantung-paru.

Tabel 1. Hasil deskripsi data kekuatan altit bulutangkis Maluku Utara pada POMNAS Tahun 2019

\begin{tabular}{|l|c|c|c|c|}
\hline & $\begin{array}{c}\text { Kekuatan otot } \\
\text { jari tangan }\end{array}$ & $\begin{array}{c}\text { Kekutan otot } \\
\text { lengan dan bahu }\end{array}$ & $\begin{array}{c}\text { Kekuatan } \\
\text { otot tungkai }\end{array}$ & $\begin{array}{c}\text { Kekuatan otot } \\
\text { punggung }\end{array}$ \\
\hline Jumlah & 167,2 & 107 & 575 & 465 \\
\hline Rata-Rata & 41,80 & 26,75 & 143,75 & 116,25 \\
\hline Simpang Baku & 4,003 & 5,252 & 68,670 & 4,646 \\
\hline Varians & 16,027 & 27,583 & 4715,583 & 21,583 \\
\hline Nilai Tinggi & 46,8 & 30 & 243 & 121 \\
\hline Nilai Rendah & 37,6 & 19 & 88 & 110 \\
\hline Rentang & 9,2 & 107 & 575 & 465 \\
\hline
\end{tabular}


JUPE: Jurnal Pendidikan Mandala

http://ejournal.mandalanursa.org/index.php/JUPE/index

Tabel 2. Hasil deskripsi data daya ledak altit bulutangkis Maluku Utara pada POMNAS

Tahun 2019

\begin{tabular}{|l|c|c|}
\hline & $\begin{array}{c}\text { Daya ledak otot lengan } \\
\text { dan bahu }\end{array}$ & $\begin{array}{c}\text { Daya ledak otot } \\
\text { tungkai }\end{array}$ \\
\hline Jumlah & 18 & 248,5 \\
\hline Rata-Rata & 4,5 & 62,125 \\
\hline Simpang Baku & 0,355 & 9,936 \\
\hline Varians & 0,127 & 98,729 \\
\hline Nilai Tinggi & 5 & 73 \\
\hline Nilai Rendah & 4,2 & 52,5 \\
\hline Rentang & 0,8 & 20,5 \\
\hline
\end{tabular}

Tabel 3. Hasil deskripsi data kelentukan altit bulutangkis Maluku Utara pada POMNAS

Tahun 2019

\begin{tabular}{|l|l|}
\hline & Kelentukan \\
\hline Jumlah & 142,3 \\
\hline Rata-Rata & 35,575 \\
\hline Simpang Baku & 10,910 \\
\hline Varians & 119,043 \\
\hline Nilai Tinggi & 46,7 \\
\hline Nilai Rendah & 22 \\
\hline Rentang & 24,7 \\
\hline
\end{tabular}

Tabel 4. Hasil deskripsi data kecepatan altit bulutangkis Maluku Utara pada POMNAS

Tahun 2019

\begin{tabular}{|l:l} 
& Kecepatan \\
\hline Jumlah & 25,04 \\
\hline Rata-Rata & 6,26 \\
\hline Simpang Baku & 0,642 \\
\hline Varians & 0,413 \\
\hline Nilai Tinggi & 7,10 \\
\hline Nilai Rendah & 5,55 \\
\hline Rentang & 1,55
\end{tabular}

Tabel 5. Hasil deskripsi data daya tahan otot altit bulutangkis Maluku Utara pada POMNAS Tahun 2019

\begin{tabular}{|l|c|c|c|}
\hline & $\begin{array}{c}\text { Daya tahan } \\
\text { otot perut }\end{array}$ & $\begin{array}{c}\text { Daya tahan otot } \\
\text { lengan dan bahu }\end{array}$ & $\begin{array}{c}\text { Daya tahan } \\
\text { otot tungkai }\end{array}$ \\
\hline Jumlah & 266 & 212 & 346 \\
\hline Rata-Rata & 66,50 & 53,00 & 86,50 \\
\hline Simpang Baku & 13,229 & 9,764 & 16,763 \\
\hline Varians & 175,000 & 95,333 & 281,000 \\
\hline Nilai Tinggi & 86 & 66 & 111 \\
\hline Nilai Rendah & 57 & 45 & 73 \\
\hline Rentang & 29 & 21 & 38 \\
\hline
\end{tabular}

Vol. 4. No. 5 Desember 2019 p-ISSN: 2548-5555 e-ISSN:2656-6745

Tabel 6. Hasil deskripsi data daya tahan jantung-paru altit bulutangkis Maluku Utara pada POMNAS Tahun 2019

\begin{tabular}{|l|c|}
\hline & Daya tahan jantung-paru \\
\hline Jumlah & 213 \\
\hline Rata-Rata & 53,25 \\
\hline Simpang Baku & 6,995 \\
\hline Varians & 48,937 \\
\hline Nilai Tinggi & 61,7 \\
\hline Nilai Rendah & 45,7 \\
\hline Rentang & 16 \\
\hline
\end{tabular}

Tabel 7. Hasil nilai konversi kondisi fisik atlit bulutangkis Maluku Utara pada POMNAS Tahun 2019

\begin{tabular}{|c|c|c|c|c|}
\hline No & Kategori & Konversi Nilai & Frekuensi & $\mathbf{F}(\%)$ \\
\hline 1 & Sempura & $>10$ & 0 & 0,00 \\
\hline 2 & Baik Sekali & $8-9$ & 0 & 0,00 \\
\hline 3 & Baik & $6-7$ & 4 & 100,00 \\
\hline 4 & Cukup & $4-5$ & 0 & 0,00 \\
\hline 5 & Kurang & $<2$ & 0 & 0,00 \\
\hline \multicolumn{3}{|c|}{ Jumlah } & 4 & 100,00 \\
\hline
\end{tabular}

Berdasarkan tabel 7 diatas, tidak terdapat atlet atau 0\% yang berada pada ketegori sempurna, baik sekali, cukup dan kurang, dan terdatap 4 atlit atau $100 \%$ berada pada kategori baik. Penjelasan dalam bentuk diagram dapat dilihat pada gambar dibawah ini:

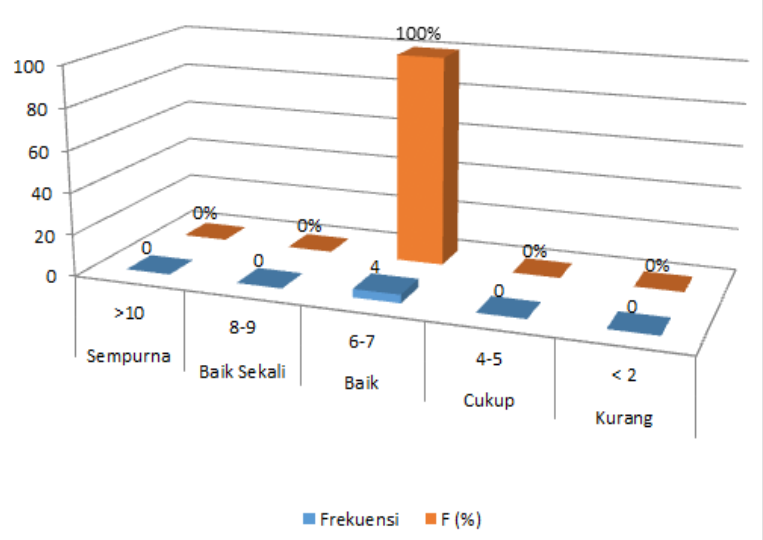

Gambar 1. Diagram hasil nilai konversi kondisi fisik atlit bulutangkis Maluku Utara pada POMNAS Tahun 2019

\section{PEMBAHASAN}

Kekuatan

(strenght), adalah kemampuan seseorang dalam mempergunakan ototnya untuk menerima beban sewaktu bekerja atau dapat juga dikatakan kemampuan otot skeleta tubuh untuk melakukan kontraksi atau tegangan maksimal dalam menerima beban sewaktu melakukan aktifitas (Halim, 2011:15). Kekuatan otot lengan yang baik dapat mempengaruhi hasil pukulan smash dengan baik pula. Dimana saat atlit melakukan 
pukulan smash dengan baik maka akan mendapatkan poin yang banyak dan dapat pula memenangkan pertandingan denagn mudah. Selain kekuatan otot lengan, faktor lainnya yang mempengaruhi pukulan smash adalah kekuatan otot tungkai. Dimana kekuatan otot tungkai ini diperlukan saat atlit mengambil ancang-angcang melompat keatas untuk melakukan pukulan smash. Pada dasarnya, dengan memiliki kekuatan otot yang baik maka dapat melakukan gerakan teknik dasar bermain bulutangkis dengan baik pula.

Daya ledak (power), adalah kemampuan seseorang untuk mempergunakan kekuatan maksimum yang dikerahkan dalam waktu yang sesingkat-singkatnya. Dalam hal ini dapat dinyatakan bahwa daya ledak (power) $=$ kekuatan (force) $\mathrm{x}$ kecepatan (velocity), seperti dalam lompat tinggi, tolak peluru serta gerak lain yang bersifat eksplosif (Halim, 2011:16). Sama halnya dengan kekuatan, daya ledak juga mempengaruhi kemampuan smash seorang atlit. Dimana saat melakukan smash lecutan pergelangan tangan saat shutllecock impac dengan raket sangat berpengaruh terhadap hasil kecepatan smash.

Kelentukan (flexibility), adalah kemampuan seseorang dalam menyesuaikan diri untuk segala aktivitas dengan kelentukan tubuh yang luas. Keleluasan kelentukan tubuh pada persendian sangat dipengaruhi oleh elastisitas otot, tendo dan ligamen sekitar sendi. Hal ini sangat mudah ditandai dengan tingkat fleksibilitas persendian pada seluruh tubuh (Halim, 2011:16). Kelentukan juga dapat mempengaruhi hasil pukulan smash, dimana kelentukan togok kebelakang saat melakukan smash akan menambah kekuatan pukulan. Semakin baik kelentukan togok kebelakan seorang atlet maka semain baik pula teknik dasar yang dimilik atlit tersebutnya khususnya teknik dasar smash.

Kecepatan (speed), adalah kemampuan seseorang untuk mengerjakan gerakan berkesinambungan dalam bentuk yang sama dalam waktu yang sesingkat-singkatnya, seperti dalam lari cepat, pukulan dalam tinju, balap sepeda dan lain-lain. Dalam hal ini ada kecepatan gerak dan kecepatan eksplosif (Halim, 2011:16). Kecepatan merupakan salah satu unsur kondisi fisik yang sangat dibutuhkan dalam cabang olahraga bulutangkis. Setiap atlit harus memiliki kecepatan yang baik untuk mengejar shuttlecook baik yang didepan net maupun yang dibelakang lapangan dekat garis out. Atlit akan mampu dengan baik melakukan berbagai macam serangan dengan cepat dan bertahan dengan baik pula ketika mendapat serangan balik dari lawan. Jika tidak memiliki kecepatan dengan baik maka atlit tersebut akan kesulitan dalam hal serangan dan bertahan dikarenakan lambat dalam melakukan gerakan.

Daya tahan otot (local endurance), adalah kemampuan seseorang dalam mempergunakan ototnya untuk berkontraksi secara terus-menerus dalam waktu yang relatif lama dengan beban tertentu (Halim, 2011:16). Daya tahan umum (general endurance), adalah kemampuan seseorang dalam mempergunakan sistem jantung, paru-paru dan peredaran darah secara efektif dan efisien untuk menjalankan kerja sercara terus menerus yang melibatkan kontraksi sejumlah otot dengan intensitas tinggi dalam waktu yang cukup lama (Halim, 2011:16). Daya tahan ini juga sangat berperngaruh terhadap semua teknik dasar bermain bulutangkis. Jika daya tahan yang dimiliki seorang atlit tidak baik maka atlit tersebut akan kesulitan dalam mengembangkan permainannya, dimana permainan bulutangkis ini membutuhkan gerakan-gerakan yang cepat, kuat, dan cenderung lama dalam melakukan pukulanpukulan relly. Untuk itu setiap atlit harus memiliki daya tahan yang baik agar dapat mengatasi permainan relly yang panjang dan lama dari pemain lawan.

\section{SIMPULAN}

Berdasarkan analisis data dan pembahasan yang telah di paparkan, maka dapat dikemukakan simpulan bahwa tingkat kondisi fisik atlit POMNAS cabang olahraga bulutangkis Tahun 2019 berada pada kategori baik.

\section{DAFTAR PUSTAKA}

Halim, Nur Ichsan. 2011. Tes dan Pengukuran Kesegaran Jasmani. Makassar: Badan Penerbit UNM Makassar.

Harsono. 1988. Coaching dan aspek-aspek dalam Caocing. Jakarta: Dirjen Dikti Depdikbud. 
PB PBSI. 1985. Pedoman Pola Pembinaan Bulutangkis Nasional. Jakarta: PB PBSI.

Sajoto, Moch. 1988. Pembinaan Kondisi Fisik dalam Olahraga. Semarang: FPOK IKIP.

Sarwono. 1990. Badminton. Surakarta: FKIP UNS.

Soekarman. 1987. Dasar Olahraga untuk Pembina, Pelatih dan Atlet. Jakarta Inti Idayu Press. http://www.mediafire.Kondisi fisik. Com. tanggal 5 Agustus 2019, Pukul 11.28 Wit.

Sugiyono. 2014. Statistika Untuk Penelitian. Bandung: Alfabeta.

Takwin, Rohandy. 2015. Analisis Tingkat Kondisi Fisik Atlet Bulutangkis Sulawesi Selatan Ditinjau dari Prestasi. Makassar: Universitas Negeri Makassar. Jurnal Nonpublikasi. 